\title{
The anatomical landmarks effective in the localisation of the median nerve during orthopaedic procedures
}

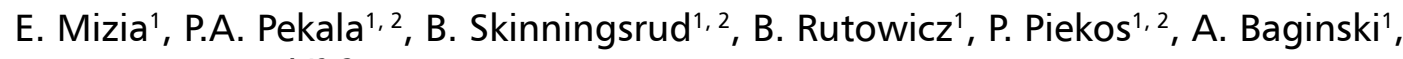 \\ K.A. Tomaszewski', 3 \\ 'Department of Anatomy, Jagiellonian University Medical College, Krakow, Poland \\ 2International Evidence-Based Anatomy Working Group, Krakow, Poland \\ ${ }^{3}$ Faculty of Medicine and Health Sciences, Andrzej Frycz Modrzewski Krakow University, Krakow, Poland
}

[Received: 10 March 2020; Accepted: 30 March 2020]

\begin{abstract}
Background: The aim of this study was to create a safe zone for surgeons who perform procedures in the wrist to avoid iatrogenic damage to the median nerve (MN) by identifying anatomical landmarks using ultrasound (USG).

Materials and methods: We measured the distances between the MN and two easily identifiable anatomical landmarks at the level of the proximal border of carpal ligament using USG.

Results: A total of 57 volunteers ( $n=114$ upper limbs) were included in this study. Our main findings revealed that the distance from the flexor carpi radialis tendon to MN (FCR-MN) was $7.87 \mathrm{~mm}$ (95\% confidence interval 7.37-8.37) and the distance from flexor carpi ulnaris tendon to MN (FCU-MN) was $19.09 \mathrm{~mm}$ (95\% confidence interval 18.51-19.67).

Conclusions: The tendons of FCR and FCU are easily identifiable landmarks that can be distinguished using simple palpation. Based on our USG findings, the area around FCR should be carefully navigated to avoid iatrogenic injury to the MN during surgical procedures around the carpal tunnel. (Folia Morphol 2021; 80, 2: 248-254)
\end{abstract}

Key words: median nerve, flexor carpi radialis, flexor carpi ulnaris, iatrogenic injury, carpal tunnel release, anatomical landmarks

\section{INTRODUCTION}

Carpal tunnel syndrome (CTS) is one of the most common nerve compression syndromes affecting the general population [19]. This condition may cause numbness, paraesthesias, burning sensations and pain in both the hand and arm. These effects begin to appear when the median nerve (MN), which passes through a narrow passageway in the wrist called the carpal tunnel (Fig. 1), is compressed by the flexor tendons, carpal ligament, and surrounding carpal bones. It is believed that a constellation of risk factors contributes to the development of entrapping the MN. Some risk factors may include anatomical variations of the wrist, female sex, obesity, and daily repetitive hand motion to name a few [17]. Carpal tunnel syndrome is diagnosed clinically, often being confirmed by an electromyogram, while ultrasonography (USG) criteria have become increasingly useful

Address for correspondence: E. Mizia, MD, PhD, Department of Anatomy, Jagiellonian University Medical College, ul. Kopernika 12, 31-034 Kraków, Poland, tel: +48 1242295 11, e-mail: ewa.mizia@gazeta.pl

This article is available in open access under Creative Common Attribution-Non-Commercial-No Derivatives 4.0 International (CC BY-NC-ND 4.0) license, allowing to download articles and share them with others as long as they credit the authors and the publisher, but without permission to change them in any way or use them commercially. 


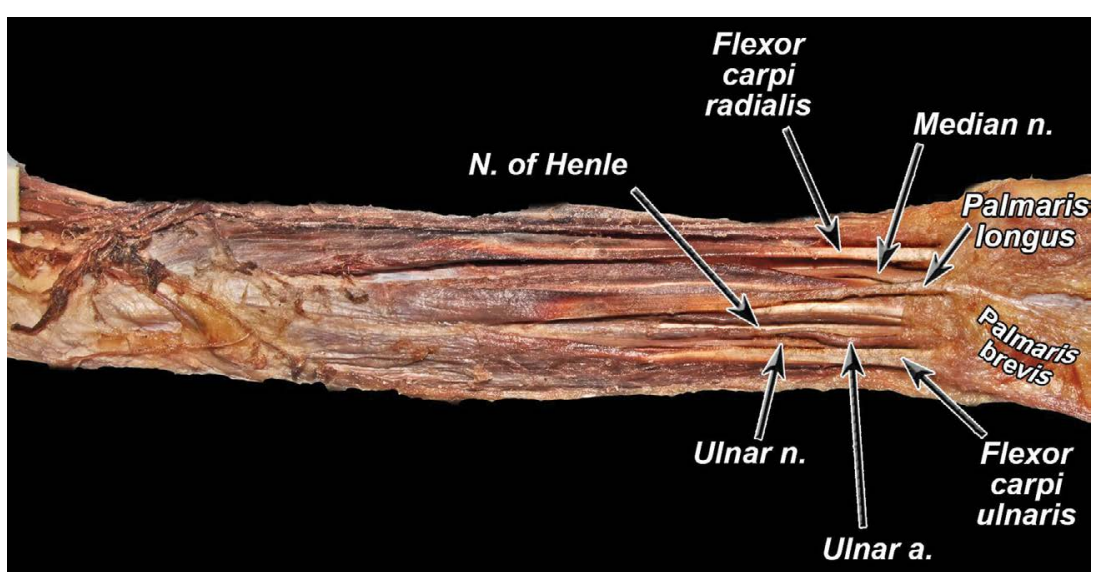

Figure 1. Cadaveric image of the wrist.

for the diagnosis. Ultrasonography is better tolerated, less expensive, yet just as effective as other diagnostic methods $[1,8]$. It provides a good indication of the severity of the condition and it allows anatomical variants to be discerned [19].

If there is an early diagnosis of CTS, wrist splinting, non-steroidal anti-inflammatory drugs, and corticosteroids are typically initiated as treatment along with other physical rehabilitation techniques [24]. Although this type of conservative treatment may be the first-line choice when treating CTS, there is little evidence to suggest it has any practical long-term success at removing symptoms. That is why surgery is the only definite option in treatment in more severe cases of CTS [9].

Surgery entails cutting through the carpal tunnel ligament thereby releasing pressure on the $\mathrm{MN}$ to hopefully eradicate any associated symptoms. This can be achieved through either an open or an endoscopic procedure, which are the two available surgical techniques [2]. Both open and endoscopic release of the flexor retinaculum in CTS has yielded satisfactory results [3]. Risks involved in this surgery include infections, improper pressure release, scar formation and most importantly possible damage to the MN.

Although carpal tunnel surgery is considered to be one of the safest procedures performed by surgeons, there is still a minute risk that the MN may be lacerated or completely cut during the operation [13]. This is one of the most serious complications. An injured $\mathrm{MN}$ results in permanent damage that can result in variable symptoms such as decreased strength, sensation, and hand function in the median nerve innervated region. Moreover, severe nerve pain may emerge with any applied pressure to the site due to the development of a painful neuroma [22].

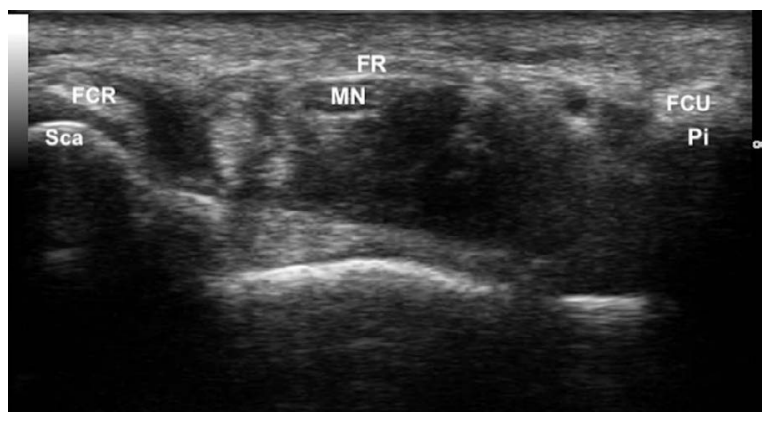

Figure 2. Cross section sonogram of carpal tunnel anatomy; FR flexor retinaculum; $\mathrm{Pi}$ — pisiform bone; $\mathrm{Sca}$ — scaphoid bone; $\mathrm{MN}$ median nerve; FCU — flexor carpi ulnaris; FCR — flexor carpi radialis.

The aim of this study was to identify a safe zone for surgeons who perform CTS release and other procedures in the wrist by analysing the anatomical variations in the course of the $\mathrm{MN}$ and its easily identifiable adjacent landmarks through the utilisation of USG.

\section{MATERIALS AND METHODS}

\section{Patients}

The local ethics committee has approved the protocol. Written and informed consent was obtained from every patient. Inclusion criteria were as follows: informed consent, no current or history of trauma in upper limbs. Exclusion criteria included: current or history of trauma of upper limbs, radiotherapy or surgery of upper limbs, rheumatoid diseases, or deformities of upper limbs.

\section{Measurements}

The following anatomical landmarks were visualised using the MyLab25 USG scanner with an $18 \mathrm{MHz}$ transducer (Fig. 2): 
- the lateral margin of the flexor carpi ulnaris (FCU) and/or its attachment to the pisiform bone (level $0=$ proximal edge of the flexor retinaculum)

- the medial margin of the tendon of flexor carpi radialis (FCR).

A line was drawn along the medial edge of the FCR tendon on the palmar surface skin of the subject. The lateral edge of the USG transducer was adjacent to this line. The following parameters were assessed distally using the transverse position of the transducer (perpendicular to the long axis of the $\operatorname{limb}$ ) at $0 \mathrm{~cm}$, $1 \mathrm{~cm}$, and $2 \mathrm{~cm}$ levels.

Level 0 (proximal edge of the flexor retinaculum):

- distance between the lateral margin of the FCU tendon and the medial margin of the $\mathrm{MN}$;

- distance between the medial edge of the FCR tendon and the lateral margin of $\mathrm{MN}$;

- transverse dimension of the MN (lateral);

- the anterior-posterior (AP) dimension of the MN. Level $1(1 \mathrm{~cm}$ distal from level 0$)$ :

- transverse dimension of the MN (lateral);

- the AP dimension of the MN.

Level 2 ( $2 \mathrm{~cm}$ distal from level 0 ):

- transverse dimension of the MN (lateral).

- the AP dimension of the MN.

\section{Statistical analysis}

To perform statistical analyses of the data obtained, elements of descriptive statistics such as mean values with standard deviations (SD) were calculated. Normal distribution was assessed using the Shapiro-Wilk test. In the case of a normal distribution, data was compared using Student's t-test. If the distribution was not normal, the Mann-Whitney $U$ test was used. Authors compared the following groups: males vs. females, left side vs. right side, dominant hand vs. non-dominant hand. A p-value of $<0.05$ was considered statistically significant. Calculations were performed using SPSS software.

\section{Ethics}

The research protocol was approved by the JagielIonian University Medical College Ethics Committee. The study was performed in accordance with the ethical standards established in the 1964 Declaration of Helsinki and its later amendments. Informed consent was obtained. The study was conducted in 2018 in the local Department of Anatomy.

\section{RESULTS}

Patients

A total of 57 patients ( $n=114$ upper limbs, 55 patients with right dominant hand, 2 patients with left dominant hand, 27 females, 30 males) were included in this study.

Median nerve dimensions on the right and left side

On the right side, MN measured $2.06 \mathrm{~mm}$ $(S D \pm 0.46), 2.02 \mathrm{~mm}(S D \pm 0.37)$, and $1.57 \mathrm{~mm}$ $(S D \pm 0.36)$ in the $A P$ dimension and $5.77 \mathrm{~mm}$ $(S D \pm 0.89), 5.52 \mathrm{~mm}(S D \pm 0.96)$, and $6.21 \mathrm{~mm}$ $(S D \pm 1.13)$ in the transverse (lateral-medial) dimension at 0,1 , and $2 \mathrm{~cm}$ distal to the proximal border of the flexor retinaculum, respectively (Table 1 ).

On the left side, MN measured $1.99 \mathrm{~mm}(S D \pm 0.45)$, $1.96 \mathrm{~mm}(\mathrm{SD} \pm 0.42)$, and $1.74 \mathrm{~mm}(\mathrm{SD} \pm 0.57)$ in the $A P$ dimension and $5.78 \mathrm{~mm}(S D \pm 1.10)$, $5.88 \mathrm{~mm}(S D \pm 1.09)$, and $6.21 \mathrm{~mm}(S D \pm 1.14)$ in the lateral-medial dimension at 0,1 , and $2 \mathrm{~cm}$ distal to the proximal border of the flexor retinaculum, respectively. There were no statistically significant differences between sexes (Table 1).

\section{Median nerve dimensions on the dominant and non-dominant hand}

On the dominant hand, MN measured $2.05 \mathrm{~mm}$ (SD \pm 0.46$), 2.02 \mathrm{~mm}$ (SD \pm 0.37 ), and $1.58 \mathrm{~mm}$ $(S D \pm 0.37)$ in the $A P$ dimension and $5.75 \mathrm{~mm}$ $(S D \pm 0.87), 5.54 \mathrm{~mm}(S D \pm 0.96)$, and $6.17 \mathrm{~mm}$ $(S D \pm 1.13)$ in the lateral-medial dimension at 0,1 , and $2 \mathrm{~cm}$ distal to the proximal border of the flexor retinaculum, respectively (Table 2 ).

On the non-dominant hand, MN measured $1.99 \mathrm{~mm}$ (SD \pm 0.45$), 1.97 \mathrm{~mm}$ (SD \pm 0.41 ), and $1.73 \mathrm{~mm}$ $(S D \pm 0.57)$ in the $A P$ dimension and $5.86 \mathrm{~mm}$ (SD \pm 1.07), $5.91 \mathrm{~mm}$ (SD \pm 1.06$)$, and $6.28 \mathrm{~mm}$ $(S D \pm 1.12)$ in the lateral-medial dimension at 0,1 , and $2 \mathrm{~cm}$ distal to the proximal border of the flexor retinaculum, respectively (Table 2 ).

\section{Anatomical landmarks measured at the level of} the proximal border of the flexor retinaculum

The distance from FCR to MN (FCR-MN) was $7.87 \mathrm{~mm}$ (95\% confidence interval [Cl] 7.37-8.37), and the distance from FCU to MN (FCU-MN) was $19.09 \mathrm{~mm}(95 \% \mathrm{Cl} 18.51-19.67)$. In regard to sex, FCR-MN was $8.76 \mathrm{~mm}(95 \% \mathrm{Cl} 8.05-9.47)$ in males and $6.89 \mathrm{~mm}(95 \% \mathrm{Cl} 6.29-7.49)$ in females, and FCU-MN 
Table 1. Median nerve dimensions measured at different levels distally from the proximal border of the carpal ligament in the right and left wrist with respect to sex

\begin{tabular}{lcccccc}
\hline Level & Sex & \multicolumn{2}{c}{ Right (mm \pm SD) } & & \multicolumn{2}{c}{ Left (mm \pm SD) } \\
\cline { 3 - 4 } \cline { 5 - 6 } & & Anteroposterior dimension & Lateral-medial dimension & & Anteroposterior dimension & Lateral-medial dimension \\
\hline $0 \mathrm{~cm}$ & Overall & $2.06 \pm 0.46$ & $5.77 \pm 0.89$ & & $1.99 \pm 0.45$ & $5.78 \pm 1.10$ \\
& Male & $2.03 \pm 0.39$ & $6.01 \pm 0.73^{*}$ & & $2.02 \pm 0.42$ & $5.93 \pm 1.09$ \\
& Female & $2.08 \pm 0.53$ & $5.51 \pm 0.99^{*}$ & & $1.95 \pm 0.48$ & $5.62 \pm 1.10$ \\
$1 \mathrm{~cm}$ & Overall & $2.02 \pm 0.37$ & $5.52 \pm 0.96$ & & $1.96 \pm 0.42$ & $5.88 \pm 1.09$ \\
& Male & $2.10 \pm 0.37$ & $5.81 \pm 0.85^{*}$ & & $1.99 \pm 0.32$ & $6.20 \pm 1.12^{*}$ \\
& Female & $1.93 \pm 0.37$ & $5.20 \pm 0.99^{*}$ & & $1.93 \pm 0.51$ & $5.53 \pm 0.96^{*}$ \\
& Overall & $1.57 \pm 0.36$ & $6.21 \pm 1.13$ & & $1.74 \pm 0.57$ & $6.21 \pm 1.14$ \\
& Male & $1.63 \pm 0.38$ & $6.43 \pm 1.09^{*}$ & & $1.74 \pm 0.33$ & $6.44 \pm 0.95^{*}$ \\
& Female & $1.50 \pm 0.34$ & $5.97 \pm 1.14^{*}$ & & $1.74 \pm 0.76$ & $5.96 \pm 1.28^{*}$ \\
\hline
\end{tabular}

${ }^{*}$ Statistically significant differences between males and females; SD — standard deviation

Table 2. Median nerve dimensions measured at different levels distally from the proximal border of the carpal ligament in the dominant and non-dominant hand

\begin{tabular}{lccccc}
\hline Level & \multicolumn{2}{c}{ Dominant (mm \pm SD) } & & \multicolumn{2}{c}{ Non-dominant (mm \pm SD) } \\
\cline { 2 - 3 } \cline { 5 - 6 } & Anteroposterior dimension & Lateral-medial dimension & & Anteroposterior dimension & Lateral-medial dimension \\
\hline $0 \mathrm{~cm}$ & $2.05 \pm 0.46$ & $5.75 \pm 0.87$ & & $1.99 \pm 0.45$ & $5.86 \pm 1.07$ \\
$1 \mathrm{~cm}$ & $2.02 \pm 0.37$ & $5.54 \pm 0.96$ & & $1.97 \pm 0.41$ & $5.91 \pm 1.06$ \\
$2 \mathrm{~cm}$ & $1.58 \pm 0.37$ & $6.17 \pm 1.13$ & & $1.73 \pm 0.57$ & $6.28 \pm 1.12$ \\
\hline
\end{tabular}

*No statistically significant differences between dominant and non-dominant upper limbs; SD — standard deviation

Table 3. Anatomical landmarks measured at the level of proximal border of carpal ligament

\begin{tabular}{|c|c|c|c|c|c|c|}
\hline \multirow[t]{2}{*}{ Sex } & \multicolumn{2}{|c|}{ Right (mm $\pm 95 \%$ Cl) } & \multicolumn{2}{|c|}{ Left (mm $\pm 95 \% \mathrm{Cl})$} & \multicolumn{2}{|c|}{ Overall $(\mathrm{mm} \pm 95 \% \mathrm{Cl})$} \\
\hline & FCR-MN & FCU-MN & FCR-MN & FCU-MN & FCR-MN & FCU-MN \\
\hline Overall & $8.24^{*}(7.49-8.99)$ & $19.00(18.22-19.78)$ & $7.50 *(6.85-8.15)$ & 19.18 (18.33-20.03) & $7.87(7.37-8.37)$ & 19.09 (18.51-19.67) \\
\hline Male & $9.20^{*}(8.13-10.27)$ & $20.08(19.12-21.04)$ & $8.31 *(7.38-9.24)$ & 20.11 (18.99-21-23) & $8.76(8.05-9.47)$ & 20.09 (19.36-20.82) \\
\hline Female & $7.19^{*}(6.29-8.10)$ & $17.80^{*}(16.69-18.91)$ & $6.60^{*}(5.82-7.38)$ & $18.16^{*}(16.96-19.36)$ & $6.89(6.29-7.49)$ & $17.98(17.17-18.79)$ \\
\hline
\end{tabular}

${ }^{*}$ Significant differences between right and left upper limbs; Cl — confidence interval; FCR-MN — flexor carpi radialis tendon-median nerve; FCU-MN — flexor carpi ulnaris tendon-median nerve

was $20.09 \mathrm{~mm}(95 \% \mathrm{Cl}$ 19.36-20.82) in males and $17.98 \mathrm{~mm}$ (95\% Cl 17.17-18.79) in females (Table 3).

With respect to side, on the right, FCR-MN was $8.24 \mathrm{~mm}$ (95\% Cl 7.49-8.99) and FCU-MN was $19.00 \mathrm{~mm}$ (95\% Cl 18.22-19.78). In males, FCR-MN was $9.20 \mathrm{~mm}(95 \% \mathrm{Cl} 8.13-10.27)$ and FCU-MN was $20.08 \mathrm{~mm}$ (95\% Cl 19.12-21.04). In females, FCR-MN was $7.19 \mathrm{~mm}(95 \% \mathrm{Cl} 6.29-8.10)$ and FCU-MN was $20.08 \mathrm{~mm}$ (95\% Cl 19.12-21.04) (Table 3).

On the left side, FCR-MN was $7.50 \mathrm{~mm}(95 \%$ $\mathrm{Cl}$ 6.85-8.15) and FCU-MN was $19.18 \mathrm{~mm}(95 \% \mathrm{Cl}$ 18.33-20.03). In males, FCR-MN was $8.31 \mathrm{~mm}(95 \%$ $\mathrm{Cl} 7.38-9.24)$ and FCU-MN was $20.11 \mathrm{~mm}(95 \% \mathrm{Cl}$ 18.99-21.23). In females, FCR-MN was 6.60 mm (95\%
$\mathrm{Cl} 5.82-7.38)$ and FCU-MN was $18.16 \mathrm{~mm}(95 \% \mathrm{Cl}$ 16.96-19.36) (Table 3).

\section{DISCUSSION}

This study aimed to show how one can assess the position of MN using simple and well distinguished anatomical landmarks without the use of radiological techniques. This was achieved by analysing the anatomical variations in the course of the $\mathrm{MN}$, the FCU with its attachment to the pisiform, and the FCR through the utilisation of USG. These anatomical structures can be clearly seen through the skin of the wrist, after surgical opening, and after trauma involving a laceration that exposes this area of the wrist. 
We found that FCR-MN was $7.87 \mathrm{~mm}(95 \% \mathrm{Cl}$ 7.37-8.37) and FCU-MN was $19.09 \mathrm{~mm}(95 \% \mathrm{Cl}$ 18.51-19.67). The tendons of FCR and FCU are easily identifiable landmarks that can be distinguished in every patient through the skin using simple palpation. The safe zone from FCR is $7.37 \mathrm{~mm}-95 \%$ of MNs are located within this distance - and going further medially would be a risk to injuring the MN iatrogenically. Laterally from the FCU, the safe zone is $18.51 \mathrm{~mm}-95 \%$ of MNs are located in this area. There were also statistically significant differences between right and left upper limbs and males and females (Table 3). Knowledge of these anatomical landmarks can help prevent iatrogenic damage to the MN during carpal tunnel release and other surgical procedures in the wrist.

Carpal tunnel syndrome release is the most frequently performed surgical procedure in the wrist as CTS is the most common musculoskeletal disorder in both Europe and North America [4, 5, 7, 19]. The annual incidence of its diagnosis in the general population is thought to be around 3.8/1000 [19]. The incidence of CTS peaks between the ages of 40 to 60 years and it affects from 1 to $2 / 1000$ men and 4 to 5/1000 women [4].

When there is a severe case or medical treatment for CTS fails, surgical intervention becomes the only alternative. Surgical treatment has many benefits to patients at this stage of CTS treatment as it may halt the development of motor deficits and resolve all symptoms. Since the 1990s, carpal tunnel release frequency has increased and according to the French Agency for Hospital Information (ATIH), they have increased from 9537 cases in 1995 to 142,405 in 2005 [5]. In the United States, 576,924 carpal tunnel releases were performed in 2006 as comparison [7].

The muscles of both the anterior forearm and of the thenar eminence, which control hand movement, are supplied by the MN. All forearm flexors, excluding the FCU and the portion of the flexor digitorum profundus which controls the fourth and fifth digits, are innervated by the MN. Additionally, the MN innervates the first and second lumbrical muscles and the muscles of the thenar eminence through the recurrent thenar branch. Innervation to the skin on the palmar side of the index finger, thumb, middle finger, half the ring finger thumb, and respective nail beds are also supplied by the MN.

Deficits in motor and sensory functions in areas supplied by the MN depend on the type of injury and at which level the MN has sustained it. In CTS, motor and sensory deficits occur due to compression of the MN within the wrist. Motor deficits include weakness in flexion of the radial half of the digits and of the thumb and weakness in abduction and opposition of the thumb. Furthermore, the presence of an ape hand deformity may be present when attempting to form a fist also known as the benediction sign [23]. Sensory deficits include numbness and tingling in lateral 3.5 digits and their respective nail beds but not in the thenar eminence. Unlike in wrist laceration, sensation still persists in the central palm in CTS. This is due to the fact that the palmar cutaneous branch runs above the flexor retinaculum and is not affected in CTS.

A large retrospective review of 1332 CTS releases performed by two fellowship-trained hand surgeons at university hospitals from July 1993 to August 2006 concluded that the Indiana Tome technique can be used by experienced hand surgeons, offers early resumption of preoperative activities ( 2 days and 3 weeks), and has a low complication rate [11]. Eleven $(0.83 \%)$ complications were noted out of 1332 cases by the 2 surgeons. Numbness and hypersensitivity in the third digital nerve distribution was the most common complication. Two of these 8 patients had normal 2-point discrimination and the other 6 had persistently 2-point discrimination greater than $10 \mathrm{~mm}$ despite resolution of preoperative paraesthesia symptoms [11].

Other commonly performed surgeries in the wrist include tendon repair [25], ganglion removal [10], MCP joint replacement [6], and trapeziectomy [16]. There are reports that the MN has been mistakenly harvested instead of the palmaris longus tendon which is commonly used as a tendon graft $[12,20]$. Knowledge of relevant anatomy is, therefore, crucial to avoid inadvertent harvesting of the MN. The palmaris longus tendon is superficial to the antebrachial fascia at the wrist crease, and if it is absent, the MN will be the next most obvious midline structure [15]. In all the above-mentioned procedures, the MN may be in danger of iatrogenic injury and surgeons must be conscientious of its course and presence.

Recently, studies have proven that USG may serve as an irreplaceable and effective tool for surgeons who look to identify small nerves and calculating their risk of iatrogenic injury before procedures [21]. Identifying areas of risk allows for the creation of a safe zone for surgeons when performing various techniques involved in CTS surgery [18]. This safe zone, which can 
be located through landmarks easily seen through the skin, stresses the importance of long-term memory of clinical anatomy, surgical awareness, and the training of surgical technique. Visualisation of the MN preoperatively or during an injection can be done with USG, but in case the operator lacks the appropriate skills or an USG scanner is unavailable, landmarks should be known. Ultimately, proper anatomical knowledge provided by the safe zone may help surgeons avoid iatrogenic injury to the $\mathrm{MN}$ while decompressing the carpal tunnel [18]. Other examples of safe zones established with USG includes the posterolateral approach to the sural nerve [14] and the infrapatellar branch of the saphenous nerve during tendon graft harvesting for knee ligament reconstruction [21].

Ultrasound has limited resolution even though it is now considered to be the best diagnostic tool to visualise nerves in real-time. This limited resolution may cause those who use USG examination to miss nerve terminal branches. The authors in this study, however, successfully tracked the MN within the borders of examined areas in all cases. Additionally, another limitation found in this study is the fact that the MN is in constant motion and changes positions as it runs between other anatomical structures. The authors minimised this limitation by examining all the limbs in the identical position the limb would be placed during a CTS release procedure. Observation bias was also held to a minimum by having two experienced surgeons present during the entirety of all examinations and having a third physician aid in unclear cases.

To the best of the knowledge of the authors, this is the first study to generate a topographic anatomical model created based on reliable clinical simulations to identify areas at high risk for iatrogenic MN injury. By revealing the course and position of the MN and its adjacent anatomical landmarks, we hope to provide crucial information to surgeons on the optimal technique to avoid iatrogenic $\mathrm{MN}$ injury while operating on the wrist.

\section{CONCLUSIONS}

The results obtained in this study are an anatomical overview of the anatomy and topography of the MN region. Using simple palpation, the tendons of the FCR and the FCU can be used as landmarks to help improve anatomical awareness of the MN, to effectively plan surgery, and to provide a surgical tool for physicians to ultimately avoid iatrogenic MN injury. The safe zone medially from FCR is $7.37 \mathrm{~mm}$ and the safe zone laterally from the FCU is $18.51 \mathrm{~mm}$.

\section{REFERENCES}

1. Aggarwal A, Srivastava DN, Jana M, et al. Comparison of different sequences of magnetic resonance imaging and ultrasonography with nerve conduction studies in peripheral neuropathies. World Neurosurg. 2017; 108: 185-200, doi: 10.1016/j.wneu.2017.08.054, indexed in Pubmed: 28842238.

2. Atroshi I, Hofer M, Larsson GU, et al. Extended follow-up of a randomized clinical trial of open vs endoscopic release surgery for carpal tunnel syndrome. JAMA. 2015; 314(13): 1399-1401, doi: 10.1001/jama.2015.12208, indexed in Pubmed: 26441187.

3. Beris $A E$, Lykissas MG, Kontogeorgakos VA, et al. Anatomic variations of the median nerve in carpal tunnel release. Clin Anat. 2008; 21(6): 514-518, doi: 10.1002/ca.20650, indexed in Pubmed: 18567020.

4. Ghasemi-Rad M, Nosair E, Vegh A, et al. A handy review of carpal tunnel syndrome: from anatomy to diagnosis and treatment. World J Radiol. 2014; 6(6): 284-300, doi: 10.4329/wjr.v6.i6.284, indexed in Pubmed: 24976931.

5. Haute Autorité De Santé (HAS). Rapport HAS — Chirurgie du syndrome du canal carpien: approche multidimensionnelle pour une décision pertinente 2012.

6. Houdek MT, Wagner ER, Rizzo M, et al. Metacarpophalangeal joint arthroplasty in the setting of trauma. J Hand Surg Am. 2015; 40(12): 2416-2420, doi: 10.1016/j. jhsa.2015.09.012, indexed in Pubmed: 26527597.

7. Jain NB, Higgins LD, Losina E, et al. Epidemiology of musculoskeletal upper extremity ambulatory surgery in the United States. BMC Musculoskelet Disord. 2014; 15: 4, doi: 10.1186/1471-2474-15-4, indexed in Pubmed: 24397703.

8. Kanafi Vahed L, Arianpur A, Gharedaghi M, et al. Ultrasound as a diagnostic tool in the investigation of patients with carpal tunnel syndrome. Eur J Transl Myol. 2018; 28(2): 7380, doi: 10.4081/ejtm.2018.7406, indexed in Pubmed: 29991986.

9. Kim PT, Lee HJ, Kim TG, et al. Current approaches for carpal tunnel syndrome. Clin Orthop Surg. 2014; 6(3): 253-257, doi: 10.4055/cios.2014.6.3.253, indexed in Pubmed: 25177448.

10. Kuliński S, Gutkowska O, Urban M, et al. Dorsal and volar wrist ganglions: the results of surgical treatment. Adv Clin Exp Med. 2019; 28(1): 95-102, doi: 10.17219/ acem/81202, indexed in Pubmed: 30070079.

11. Lee WP, Schipper BM, Goitz RJ. 13-year experience of carpal tunnel release using the Indiana Tome technique. J Hand Surg Am. 2008; 33(7): 1052-1056, doi: 10.1016/j. jhsa.2008.03.013, indexed in Pubmed: 18762096.

12. Leslie BM, Osterman AL, Wolfe SW. Inadvertent harvest of the median nerve instead of the palmaris longus tendon. J Bone Joint Surg Am. 2017; 99(14): 1173-1182, doi: 10.2106/JBJS.16.01218, indexed in Pubmed: 28719556.

13. Mathen SJ, Nosrati NN, Merrell GA. Decreased rate of complications in carpal tunnel release with hand fellowship training. J Hand Microsurg. 2018; 10(1): 26-28, doi: 10.1055/s-0037-1618913, indexed in Pubmed: 29706733.

14. Mizia E, Pękala PA, Chomicki-Bindas P, et al. Risk of injury to the sural nerve during posterolateral approach to the 
distal tibia: An ultrasound simulation study. Clin Anat. 2018; 31(6): 870-877, doi: 10.1002/ca.23205, indexed in Pubmed: 29737558.

15. Murphy RX, Jennings JF, Wukich DK. Major neurovascular complications of endoscopic carpal tunnel release. J Hand Surg Am. 1994; 19(1): 114-118, doi: 10.1016/03635023(94)90233-X, indexed in Pubmed: 8169354.

16. Naram A, Lyons K, Rothkopf DM, et al. Increased complications in trapeziectomy with ligament reconstruction and tendon interposition compared with trapeziectomy alone. Hand (NY). 2016; 11(1): 78-82, doi: 10.1177/1558944715617215, indexed in Pubmed: 27418894.

17. Ozcakir $S$, Sigirli $D$, Avsaroglu H. High wrist ratio is a risk factor for carpal tunnel syndrome. Clin Anat. 2018; 31(5): 698-701, doi: 10.1002/ca.23198, indexed in Pubmed: 29722064.

18. Ozcanli $H$, Coskun NK, Cengiz $M$, et al. Definition of a safe-zone in open carpal tunnel surgery: a cadaver study. Surg Radiol Anat. 2010; 32(3): 203-206, doi: 10.1007/ s00276-009-0498-7, indexed in Pubmed: 19337677.

19. Petrover D, Richette P. Treatment of carpal tunnel syndrome: from ultrasonography to ultrasound guided carpal tunnel release. Joint Bone Spine. 2018; 85(5): 545-552, doi: 10.1016/j.jbspin.2017.11.003, indexed in Pubmed: 29154980

20. Pękala PA, Henry BM, Pękala JR, et al. Congenital absence of the palmaris longus muscle: A meta-analysis comparing cadaveric and functional studies. J Plast Reconstr
Aesthet Surg. 2017; 70(12): 1715-1724, doi: 10.1016/j. bjps.2017.08.002, indexed in Pubmed: 28917934.

21. Pękala PA, Miza E, Henry BM, et al. Injury to the infrapatellar branch of the saphenous nerve during tendon graft harvesting for knee ligament reconstruction: An ultrasound simulation study. Clin Anat. 2017; 30(7): 868-872, doi: 10.1002/ca.22904, indexed in Pubmed: 28514510.

22. Rasulić $L$, Savić $A$, Vitošević $F$, et al. latrogenic peripheral nerve injuries-surgical treatment and outcome: 10 years' experience. World Neurosurg. 2017; 103: 841-851.e6, doi: 10.1016/j.wneu.2017.04.099, indexed in Pubmed: 28450236.

23. Seiler JG, Daruwalla JH, Payne SH, et al. Normal palmar anatomy and variations that impact median nerve decompression. J Am Acad Orthop Surg. 2017; 25(9): e194-e203, doi: 10.5435/JAAOS-D-16-00038, indexed in Pubmed: 28837460.

24. Shi Q, Bobos P, Lalone EA, et al. Comparison of the short-term and long-term effects of surgery and nonsurgical intervention in treating carpal tunnel syndrome: a systematic review and meta-analysis. Hand (N Y). 2020; 15(1): 13-22, doi: 10.1177/1558944718787892, indexed in Pubmed: 30015499.

25. Tang JB. Recent evolutions in flexor tendon repairs and rehabilitation. J Hand Surg Eur Vol. 2018; 43(5): 469-473, doi: 10.1177/1753193418773008, indexed in Pubmed: 29690810. 